\title{
Assessment of knowledge regarding anaemia and its preventive measures among lactating mothers of North Gujarat region, India
}

\author{
Pankajkumar B. Nimbalkar ${ }^{1}$, Maulik D. Joshi' ${ }^{2 *}$, Nilesh Thakor ${ }^{3}$, Avirat A. Bhatt ${ }^{4}$
}

\begin{abstract}
${ }^{1}$ Department of Obstetrics and Gynecology, Nootan Medical College and Research Center, Visnagar, Gujarat, India ${ }^{2}$ Department of Public Health, Indian Institute of Public Health, Gandhinagar, Gujarat, India ${ }^{3}$ Department of Community Medicine, GMERS Medical College and Hospital, Vadnagar, Gujarat, India ${ }^{4}$ Consultant for Children with Severe Acute Malnutrition, CDN Section, UNICEF, Gujarat, India
\end{abstract}

Received: 12 December 2019

Accepted: 04 January 2020

*Correspondence:

Dr. Maulik D. Joshi,

E-mail: researchforbetterhealth@gmail.com

Copyright: () the author(s), publisher and licensee Medip Academy. This is an open-access article distributed under the terms of the Creative Commons Attribution Non-Commercial License, which permits unrestricted non-commercial use, distribution, and reproduction in any medium, provided the original work is properly cited.

\section{ABSTRACT}

Background: Anaemia in pregnancy and lactation period has detrimental effects on maternal and child health. Objective of this study was to assess knowledge of lactating mothers regarding anaemia and its preventive measures before and after educational intervention.

Methods: The interventional study conducted in purposively selected lactating mothers attending the outpatient department of obstetrics and gynecology. Hospital ethical committee permission was obtained. After taking informed consent 100 lactating mothers were selected by systemic random sampling methods. Knowledge of lactating mothers regarding anaemia and its preventive measures was assessed by pre-designed, pre-tested and semi structured questionnaire. Health education for 30 minutes was given to selected lactating mothers. Knowledge of pregnant women for the same was assessed after health education. Thus, collected data was analyzed using Epi info 7.

Results: Awareness among lactating mothers regarding causes, signs and symptoms of anemia and dietary sources of iron was $41 \%, 26 \%$ and $5 \%$ respectively which was significantly increased to $73 \%, 56 \%$ and $42 \%$ respectively after health education. Awareness among lactating mothers regarding factors which inhibit and increase iron absorption was $31 \%$ and $22 \%$ respectively which was significantly increased to $80 \%$ and $65 \%$ respectively after health education. Out of 100 lactating mothers only $24 \%$ were aware regarding treatment of anemia.

Conclusions: Lack of awareness among lactating mothers regarding anemia and its preventive measure should be addressed by health education during hospital visits.

Keywords: Assessment, Anaemia, Knowledge, Lactating mothers, Iron deficiency

\section{INTRODUCTION}

Iron deficiency anaemia (IDA) is the most common nutritional deficiency in pregnancy. According to World Health Organization (WHO) anaemia is defined as "haemoglobin less than $11 \mathrm{gm} / \mathrm{dl}$ and a haematocrit of less than 0.33. Most women begin their pregnancy with partially or completely depleted iron reserves. Thus, the severity of the anaemia is inversely related to the amount of iron reserves. ${ }^{1}$

Anaemia is a global public health problem affecting both developing and developed countries with major consequences for human health. Anaemia in pregnancy and lactation period has detrimental effects on maternal and child health. WHO has estimated that prevalence of 
anaemia among pregnant women is $14 \%$ in developed and $51 \%$ in developing countries. ${ }^{2}$

During the period of lactation, mothers are susceptible to anaemia because of maternal iron depletion and blood loss during childbirth. ${ }^{3}$ As per National Family Health Survey- 4 (NFHS-4) prevalence of Iron deficiency anaemia (IDA) in pregnant women is $50.3 \%$ in India and $51.3 \%$ in Gujarat. ${ }^{4}$

The most common causes of iron deficiency anemia (IDA) during pregnancy and postpartum are iron deficiency and acute blood loss. Approximately $90 \%$ of cases of anemia in pregnancy and lactation period are of the iron deficiency type. ${ }^{5}$ As per National Iron Plus Initiative Programme (NIPI) iron folic acid supplementation is given to antenatal and lactating mothers. In spite of NIPI, high prevalence of anemia was seen in lactating mothers.

Nutrition is the most important factor in child health promotion, growth and development; especially during the first 2 years of life, when the speed of neuropsychomotor growth and development is greatest. The health and nutrition of mothers and their children are intimately related. Iron deficiency anemia is the most prevalent type of food deprivation in the world and it particularly affects expectant mothers and infants in developing countries. There is evidence that the transfer of iron to the fetus increases when the mother has reduced reserves. However, since the mother then becomes anemic, this transfer reduces, and the fetus becomes at risk of deficiency. There is evidence that even children with normal birth weights, but anemic mothers, will have low iron reserves at birth and are more likely to develop anemia. ${ }^{6}$

Not many studies had been conducted on the knowledge and practice regarding prevention of anemia during pregnancy and lactation period in Indian context. Therefore, the present study was undertaken to assess the knowledge of lactating mothers regarding anaemia and its preventive measures.

\section{METHODS}

The present study was an interventional study undertaken in Nootan Medical College of Visnagar city of north Gujarat region.

\section{Inclusion criteria}

- Lactating mothers who gave consent were included in the study.

\section{Exclusion criteria}

- Lactating mothers who did not give the consent and those whose child were more than 2 years old were excluded from the study.
Study population was 100 lactating mothers. Total 100 lactating mothers were interviewed. The duration of this study was August to October 2019.

Before conducting the study, approval was obtained from institutional ethical committee for human research. Data safety and confidentiality was also given due consideration. The file containing identity related details was kept password protected and the filled Performa were kept in lock with key accessible only to researcher.

Baseline knowledge of lactating mothers regarding anaemia and its preventive measures was assessed by predesigned, pre-tested and semi structured questionnaire. Questionnaire was converted in vernacular language for assessment. Single educational interventional training for 30 minutes was given to selected lactating mothers with lecture, demonstration and discussion. Post- intervention knowledge of lactating mothers for the same was assessed after training by same questionnaire.

\section{Statistical analysis}

Pre and post training assessment were done by scoring method. Data were analyzed using SPSS version 17 (trial version). Parameters such as rate, ratio and percentages were calculated. In order to have valid interpretation of rates, $95 \%$ confidence intervals $(\mathrm{CI})$ were calculated. To test the significance of the difference among the statistical parameters in different subsets of population, suitable statistical tests like chi square were applied.

\section{RESULTS}

Mean age of the lactating mothers was $24.7 \pm 1.6$ years. Out of 100 lactating mothers only $41 \%$ were aware regarding causes of anaemia, the knowledge was significantly increased to $73 \%$ after health education (Figure 1).

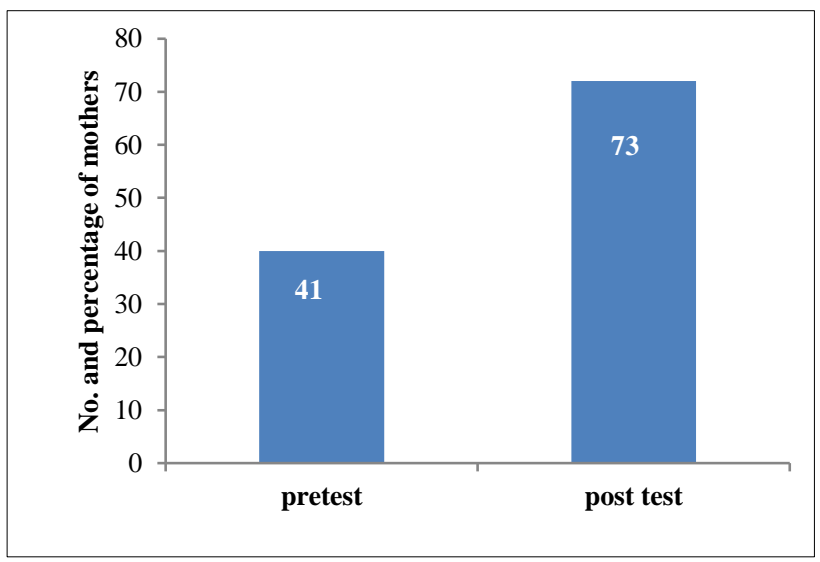

Figure 1: Pre and post-test knowledge of lactating mothers regarding causes of anaemia.

Before health education only $26 \%$ lactating mothers knew about signs and symptoms of anaemia, the 
knowledge for the same was significantly increased to $56 \%$ after health education (Figure 2).

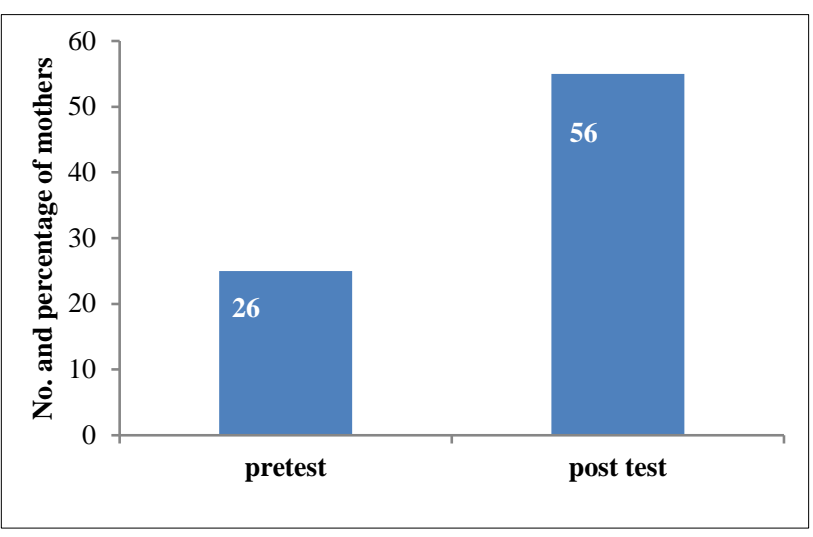

Figure 2: Pre and post-test knowledge of lactating mothers regarding signs and symptoms of anaemia before and after training.

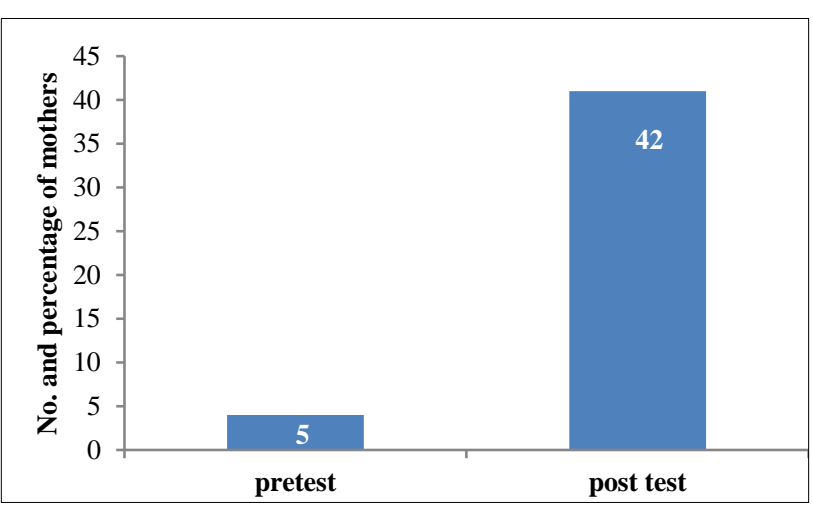

Figure 3: Pre and post-test knowledge of lactating mothers regarding sources of iron before and after training.

Baseline knowledge of the lactating mothers regarding dietary sources of iron was $5 \%$ which was significantly increased to $42 \%$ after health education (Figure 3 ).

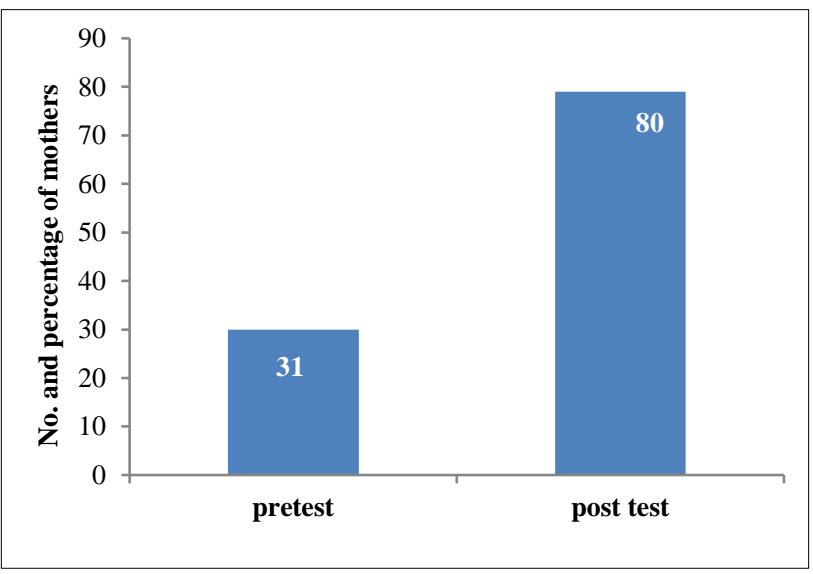

Figure 4: Pre and post-test knowledge of lactating mothers regarding factors which inhibit absorption of iron before and after training.
Very few $(31 \%)$ lactating mothers were aware regarding factors which inhibit the absorption of iron, the knowledge for the same was significantly increased to $80 \%$ after health education (Figure 4). Only 22\% lactating mothers had knowledge regarding factors which increase the absorption of iron, the knowledge for the same was significantly increased to $41 \%$ after health education (Figure 5).

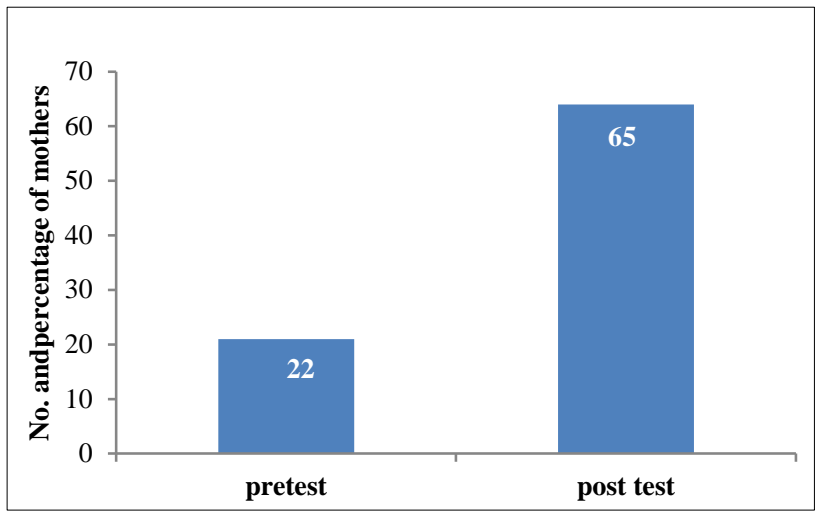

Figure 5: Pre and post-test knowledge of lactating mothers regarding factors which increase absorption of iron before and after training.

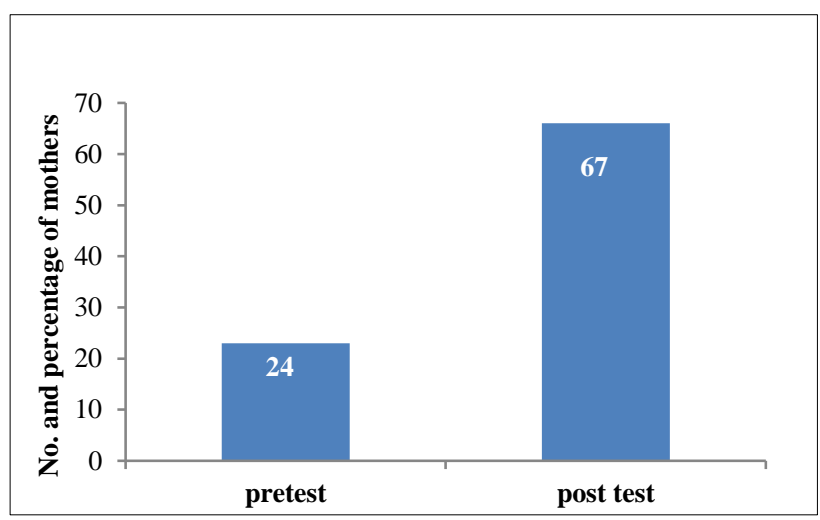

Figure 6: Pre and post-test knowledge of lactating mothers regarding treatment of anaemia.

Baseline knowledge of the lactating mothers regarding treatment of anaemia was $24 \%$ which was significantly increased to $67 \%$ after the intervention (Figure 6).

\section{DISCUSSION}

In our study mean age of the lactating mothers was $24.7 \pm 1.6$ years. Out of 100 lactating mothers only $41 \%$ were aware regarding causes of anaemia, the knowledge was significantly increased to $73 \%$ after health education. Before health education only $26 \%$ lactating mothers knew about signs and symptoms of anaemia, the knowledge for the same was significantly increased to $56 \%$ after health education. Baseline knowledge of the lactating mothers regarding dietary sources of iron was $5 \%$ which was significantly increased to $42 \%$ after health education. Very few $(31 \%)$ lactating mothers were aware 
regarding factors which inhibit the absorption of iron, the knowledge for the same was significantly increased to $80 \%$ after health education. Only $22 \%$ lactating mothers had knowledge regarding factors which increase the absorption of iron, the knowledge for the same was significantly increased to $41 \%$ after health education. Baseline knowledge of the lactating mothers regarding treatment of anaemia was $24 \%$ which was significantly increased to $67 \%$ after the intervention.

In Nimbalkar PB et al, mean age of the pregnant women was $26.6 \pm 0.9$ years. ${ }^{1}$ Baseline knowledge of the pregnant women regarding causes of anaemia was $21 \%$ which was significantly increased to $64 \%$ after the intervention. Baseline knowledge of the pregnant women regarding signs and symptoms of anaemia was $23 \%$ which was significantly increased to $66 \%$ after the intervention. Baseline knowledge of the pregnant women regarding dietary sources of iron was $40 \%$ which was significantly increased to $72 \%$ after the intervention. Baseline knowledge of the pregnant women regarding factors which inhibit the absorption of iron was $25 \%$ which was significantly increased to $55 \%$ after the intervention. Baseline knowledge of the pregnant women regarding factors which increase the absorption of iron was $4 \%$ which was significantly increased to $41 \%$ after the intervention. Baseline knowledge of the pregnant women regarding treatment of anaemia was $30 \%$ which was significantly increased to $79 \%$ after the intervention.

In Nivedita $\mathrm{K}$ et al, study showed that overall $52.5 \%$ of the participants had good knowledge regarding anemia, Iron rich food and iron supplementation but when specifically questioned only $39.87 \%$ were aware of and understood the term anemia. ${ }^{7}$ In their study, $81.96 \%$ were aware that consumption of diet poor in iron to be the reason behind anemia but knowledge about iron rich foods was lacking among our participants. $79.74 \%$ had rightly said that green leafy vegetables are a good source of iron but only $25.9 \%$ considered meat as a good source of iron.

A study by Mohammad A et al, from Pakistan showed that even though $66 \%$ of pregnant women were aware of anemia only $21 \%$ of their participants attributed lack of iron rich diet to be the cause of anemia. ${ }^{8}$ This study also found that the overall knowledge regarding iron rich foods was poor among their participants.

In Sonkar VK et al, study it was revealed that only 140 (40\%) of the participants were aware of significance of consumption of iron folic acid tablets besides regular diet. $^{9}$ Out of 350 only $221(63.14 \%)$ pregnant women consumed the iron folic acid tablets. 70 (20\%) pregnant women were taking iron folic acid tablets irregularly or not taken it daily, $59(17 \%)$ pregnant women have not at all taken iron folic acid tablets. Similarly, Balasubramaniyam et al, found that $51 \%$ had a regular intake of iron tablets, $32 \%$ had irregular intake, and $17 \%$ had not taken iron supplementation. ${ }^{10}$
This finding that a majority of the mothers had great awareness of the importance of good maternal nutrition before and during pregnancy and balanced diet is contrary to that revealed in a study by Daba et al in Ethiopia where most $(74.0 \%)$ of the respondents did not know the main food groups of the balance diet and more than half $(57.8 \%)$ of them did not even know the meaning of food. ${ }^{11}$ Also, the results of another study reported from America at El-Menshawy Hospital showed that about half of the women did not have enough knowledge regarding the meaning, the importance, and the constituents of a well-balanced diet. ${ }^{12}$

However, study done in north Gujarat region of India limits us to generalize the results. There is definitely a need for well-planned, large-scale studies using standardized methodologies to evaluate dietary practices including prevention of anaemia in lactation period among lactating mothers.

\section{CONCLUSION}

The present study indicated the lack of knowledge regarding anemia, iron rich foods and the importance of iron supplementation during lactation period. Therefore, lactating mothers should receive adequate information from health providers about anemia, iron rich diet and iron folic acid tablet supplementation during their hospital visits. It is also proposed that such repeated attempts of counselling for dietary measures of anemia can help in the prevention and correction of anemia.

\section{Funding: No funding sources}

Conflict of interest: None declared

Ethical approval: The study was approved by the Institutional Ethics Committee

\section{REFERENCES}

1. Nimbalkar PB, Patel JN, Thakor N, Patni M. Impact of educational intervention regarding anaemia and its preventive measures among pregnant women: an interventional study. Int J Reprod Contracept Obstet Gynecol. 2017;6:5317-21.

2. Sivapriya SM, Parida L. A study to assess the knowledge and practices regarding prevention of anemia among antenatal women attending a tertiary level hospital in Pune. IJSR NET. 2015;4(3):121014.

3. Lakew $\mathrm{Y}$, Biadgilign S, Haile D. Anaemia prevalence and associated factors among lactating mothers in Ethiopia: evidence from the 2005 and 2011 demographic and health surveys. BMJ Open. 2015;5(4):e006001.

4. International institute for population sciences (IIPS) and macro International. National family health survey (NFHS-4), India, 2015-16: Gujarat. Mumbai: IIPS. $2016 . \quad$ Available at: http://rchiips.org/nfhs/NFHS-4Reports/India.pdf. Accessed 3 December 2019. 
5. Ghimire N, Pandey N. Knowledge and practice of mothers regarding the prevention of anemia during pregnancy, in teaching hospital, Kathmandu. J Chitwan Med College. 2013;3(3):14-7.

6. Colomer J, Colomer C, Gutierrez D, Jubert A, Nolasco A, Donat J, et al. Anaemia during pregnancy as a risk factor for infant iron deficiency: report from the valencia infant anaemia cohort (VIAC) Study. Paediatr Perinat Epidemiol. 1990;4:196-204.

7. Nivedita K, Shanthini FN. Knowledge, attitude and practices of pregnant women regarding anemia, iron rich diet and iron supplements and its impact on their hemoglobin levels. Int J Reprod Contracept Obstet Gynecol. 2016;5:425-31.

8. Mohammad A, Rizvi. F, Irfan G. Impact of maternal education and socioeconomic status on maternal nutritional knowledge and practices regarding iron rich foods and iron supplements. Ann Pak Inst Med. Sci. 2012;8:101-5.

9. Sonkar VK, Khan NM, Domple VK, Inamdar IF. Knowledge and practices of pregnant women regarding the iron supplementation during pregnancy. Int $\mathrm{J}$ Community Med Public Health. 2017;4:2891-4.

10. Balasubramanian T, Aravazhi M, Sampath SD. Awareness of anemia among pregnant women and impact of demographic factors on their hemoglobin status. Int J Sci Stud. 2016;3(12):303-5.

11. Daba G, Beyene F, Fekadu H, Garoma W. Assessment of knowledge of pregnant mothers on maternal nutrition and associated factors in Guto Gida Woreda, East Wollega Zone, Ethiopia. J Nutr Food Sci. 2013;3:235.

12. Latifa MF, Manal HA, Nihal SS. Nutritional Awareness of women during pregnancy. J Am Sci. 2012;8(7):494-502.

Cite this article as: Nimbalkar PB, Joshi MD, Thakor N, Bhatt AA. Assessment of knowledge regarding anaemia and its preventive measures among lactating mothers of North Gujarat region, India. Int J Reprod Contracept Obstet Gynecol 2020;9:1055-9. 